\author{
Heather Hill \\ University of Western Ontario, London, Ontario, Canada
}

\title{
PUBLIC LIBRARY STAFF EXPERIENCES OF ACCOMMODATION IN THE WORKPLACE (poster)
}

\begin{abstract}
Résumé:
Identifying as having a disability in the workplace can be a complicated proposition. This research examines public library staff experiences of accommodation for a disability within the workplace. Semi-structured interviews were conducted with Canadian public library staff who sought accommodation in their workplace.
\end{abstract}

\section{Introduction}

Identifying as having a disability in the workplace can be a complicated proposition. There can be some significant stresses in contemplating whether or not to seek accommodation (Dong, Warner, Mamboleo, \& Zalles, 2017). In the best circumstances, disclosure results in accommodations that create a more accessible environment for the employee. In less than positive outcomes, disclosing can result in significant push back or delays in getting accommodation (Pionke, 2019; Gewurtz, Langan, \& Shand, 2014; House, 2021; Schomberg, 2018).

For those with visible disabilities there is no option to not identify. For those with invisible disabilities, considering disclosure of a disability can result in the 'predicament of disclosure' where there are both significant potential benefits and disadvantages to doing so (Prince, 2017). The 'predicament of disclosure' includes the uncertainties around how accommodation requests will be received, uncomfortableness around having to disclose personal information, and concerns about negative future interactions even if accommodations are provided (Prince, 2017; Dong et al, 2017).

Libraries in Canada have guidance through provincial legislation for the hiring and accommodating of disabled staff. Additionally, the Canadian Federation of Library Association's Guidelines on Library and Information Services for People with Disabilities notes the importance of recruiting, employing, and accommodating persons with disabilities into the library profession. Even with these mandates, people with disabilities are severely underrepresented within library staffs. The Canadian Association of Professional Academic Librarians (CAPAL) found in their most recent census that just under $6 \%$ of their members identify as having a disability (2018). No specific statistics are available for Canadian public libraries, but the American Library Association (ALA) reported an even smaller representation of disability with only $2.9 \%$ of their members identifying as having a disability (2017).

Given these small percentages, understanding these people's experiences in the workplace in seeking accommodation is vital to creating a more equitable employment environment in libraries. Specifically for this research, the focus is on Canadian public library staff who identify 
as having a disability and who have sought accommodation in the workplace. This research seeks to answer the following question: What is the experience of disabled Canadian public library workers who seek accommodation?

\section{Terminology}

There is flux in the disability community and in society as to whether one uses person-first language (i.e. "person with a disability") or identity-first language (i.e. "disabled person") (Dunn, 2015; Laura [@eponinetaire], 2020; Evans, D. [@dominickevans], 2019; Michele [@RebelWheelsNYC], 2017; Jamie [@BlindFury_5428], 2019; k. [@mutant_robot], 2017). Both phrases are used in the community and thus, both are used in this research.

\section{Defining Disability}

There is a saying in the disability studies literature that non-disabled people are only temporarily so (Hughes, 2007). Through age or accident, we will all be disabled at some point. Bichenbach et al. (1999, p 1184) note that disablement "is an intrinsic feature of the human condition, not a difference that essentially marks one subpopulation off from another." As such, this research takes a purposefully broad understanding of disability. Disability or impairment may consist of a wide variety of phenomena that may be permanent or temporary (such as a broken limb) or it may be dynamic - where periods of lack of impairment are followed by periods of impairment.

\section{Literature}

\section{Accommodation}

Accommodations vary by profession, but the most common accommodations sought in the workplace include adjustments to the job interview, a special chair or ergonomic workstation, flexibility of scheduling (including work from home), modified training or supervision, modified job duties, modified work environment (lighting, quiet), changes in workplace culture and the procedures in the accommodation process itself (Statistics Canada, 2019; McDowell \& Fossey, 2015; Lindsay et al., 2021; Padkapayeva, et al, 2017).

Choosing to disclose is not, however, without anxiety. There are challenges to deciding whether or not to disclose. People fear stigmatization, they may want to maintain certain barriers that disclosure would dissolve, they may want to retain confidentiality of their situation (Toth \& Dewa, 2014). Other barriers to disclosing involve an employee's lack of confidence in requesting accommodation, their fears about what will happen once they disclose (Dong et al., 2017). There can be concerns that disclosure will result in stigmatization and fears of being negative work situations due to disclosure (e.g. demotion or being overlooked for a promotion) (Prince 2017). As well, social demands of a job and workplace culture are factors in choosing to seek accommodation (Lindsay, et al. 2021).

Seeking accommodation is no guarantee that accommodations will be granted. A report from Statistics Canada noted that "Of those who required workplace accommodations: $59 \%$ had all of their needs met, $19 \%$ had some of their needs met, and 21\% had none of their needs met" (2019). Another study from Canada noted that the precarious-ness of labour also has an impact on accommodations. Shuey and Jovic (2013) found that "despite disability legislation, practices of workplace disability accommodations parallel the unequal distribution of other labor market protections, with workers in more precarious arrangements (i.e. those in nonpermanent, lowwage, and non-union jobs) at greater risk of having unmet needs" (174). The Canadian Union of 
Public Employees (CUPE) notes that 28\% of CUPE library staff are not working full time or in permanent positions and that $70 \%$ of library clerks work part time (2017).

\section{Libraries and disability}

Most of the research around disability, accessibility and libraries, focuses on people with disabilities as users of libraries. Studies generally focus on the online environment, the physical environment, and how accessibility is discussed on library websites and databases, (Hill, 2013; Gibson, Bowen, \& Hanson, 2021). Through these studies the focus is almost universally the idea of persons with disability as users of libraries.

What has been missing until recently is a focus on disabled library workers themselves. There has been a growing area of literature outlining challenges that disabled library workers face in the workplace. This literature includes personal stories of experiences in hiring practices and in the workplace (Pionke, 2019; House, 2021; Schomberg, 2018) as well as research. From the research, many disabled library staff are currently 'passing' as non-disabled and do not disclose at work as they feel disclosure of their disability might affect their career (Brown \& Sheidlower, 2019). "Stigma, harassment, ableism, and an institutional culture that values overwork" are significant components of being a library staff member with a disability (Pionke, 2019; Oud, 2019; Schomberg \& Highby, 2020). In looking at disclosure of disability within the workplace, library staff with disabilities have found that some of their colleagues were uncomfortable with the idea of disability and having a disabled colleague and noted that participants had mixed feelings about choosing to disclose that they had a disability (Oud, 2019).

The literature so far is helpful for understanding the experience of library staff with disabilities but much of it is situated within the United States (Brown \& Sheidlower, 2019; Schomberg \& Highby, 2020; Pionke, 2019) or focused on the academic library environment (Pionke, 2019; Oud, 2019) The research around the employment of librarians and library staff with disabilities is still underdeveloped, particularly within the Canadian context. This research aims to address the gap around knowledge of the experience of Canadian public library staff with disabilities by investigating their experiences seeking accommodation in the workplace. This research aims to shed light on the accommodations process in libraries and the experiences of disabled library staff in seeking it in the hopes of helping to create a more accessible environment in libraries.tw

\section{Method}

In the spring of 2021, in-depth, semi-structured interviews were conducted with library staff from libraries across Canada. Participants took part in a semi-structured interview via Zoom. Interviews were audio recorded and transcribed by the researcher. The transcripts were subjected to an interpretive phenomenological analysis (IPA) (VanScoy \& Evenstad, 2015; Smith, Flowers, \& Larkin, 2009). The goal of IPA is "to explore in detail how participants are making sense of their personal and social world” (Smith \& Osborn, 2003 p.53).

\section{Findings}

Findings to be presented in June

\section{References:}


ALA (2017). January 2017 Demographics update. http://www.ala.org/tools/research/initiatives/membershipsurveys

Bichenbach, J.E., Chatterji, S., Badley, E.M., \& Ustun, T.B. (1999). Models of disablement, universalism and the international classification of impairments, disabilities, and handicaps. Social Science \& Medicine 48, 1173-1187.

Brown, R, \& Sheidlower, S. (2019). Claiming our space: A Quantitative and Qualitative picture of disabled librarians. Library Trends, 67(3), 471-486.

CAPAL (2018). Census of Academic Librarians. https://capalibrarians.org/statements/census-ofacademic-librarians/

Canadian Union of Public Employees. (2017). Employment increasingly precarious in public libraries, survey finds. https://cupe.ca/employment-increasingly-precarious-publiclibraries-survey-finds

Dunn, D., \& Andrews, E. (2015). Person-first and identity-first language: Developing psychologists' cultural competence using disability language. American Psychologist, 70(3), 255-264.

Dong, S., Warner, A., Mamboleo, G., Guerette, A., \& Zalles, M. Z. (n.d.). Barriers in Accommodation Process Among Individuals with Visual Impairments. 83(2), 10. Keith.pdf. (n.d.).

Evans, Dominick [@dominickevans]. (2019, June 17). I am not a “person with a disability.” Stop calling me that! It's gross and full of (regular and internalized) ableism! [Tweet]. https://twitter.com/dominickevans/status/1140805608351944705

Gewurtz, R, Langan, S, \& Shand, D. (2016). Hiring people with disabilities: A scoping review. Work 54(1), 135-148.

Gibson, A., Bowen, K., Hanson, D. (2021). We need to talk about how we ralk about disability: A critical quasi-systematic review. In the Library with the Lead Pipe, https://www.inthelibrarywiththeleadpipe.org/2021/disability/

House, N. (INALJ). 2021, Jan 29). "It is exhausting as someone looking for a job in HR or LIS to see (still see, as I have been seeing these for 10+ years doing INALJ) so many physical requirements like standing and lifting that are not necessary to actually do the jobs :/ and never mentions of accommodations" [Tweet]. https://twitter.com/INALJNaomi/status/1355292234783010823

Hughes, B. (2007). Being disabled: Towards a critical social ontology for disability studies. Disability \& Society 22(7), 673-684.

Jamie [@BlindFury_5428]. (2019, March 30). Crikey! How many times must I say it? I am disabled. I am not a person with a disability [Tweet]. 
k. [@mutant_robot]. (2017, December 11). I am a disabled person - not a person with a disability I am a brunette - not a person with brown hairs I am short- not a person with [Tweet].

Laura [@eponinetaire]. (2020, Feb 29). I'm not "person with hearing loss" I'm autistic I'm partially deaf I'm disabled [Tweet].

https://twitter.com/eponinetaire/status/1233880842474270720

Lindsay, S., Osten, V., Rezai, M., \& Bui, S. (2021). Disclosure and workplace accommodations for people with autism: A systematic review. Disability and Rehabilitation, 43(5), 597610. https://doi.org/10.1080/09638288.2019.1635658

McDowell, C., \& Fossey, E. (2015). Workplace Accommodations for People with Mental Illness: A Scoping Review. Journal of Occupational Rehabilitation, 25(1), 197-206. https://doi.org/10.1007/s10926-014-9512-y

Michele [@RebelwheelsNYC]. (2017, December 11). I am not telling you how to identify. For me, I am not a person with a disability. I'm disabled. If I need to remind people that I [Tweet].

Oud, J. (2019). "Systemic workplace barriers for academic librarians with disabilities", College \& Research Libraries, Vol. 80 No. 2, pp. 169-194.

Padkapayeva, K., Posen, A., Yazdani, A., Buettgen, A., Mahood, Q., \& Tompa, E. (2017). Workplace accommodations for persons with physical disabilities: Evidence synthesis of the peer-reviewed literature. Disability and Rehabilitation, 39(21), 2134-2147. https://doi.org/10.1080/09638288.2016.1224276

Pionke, JJ. (2019). The impact of disbelief: On being a library employee with a disability. Library Trends 67(3), 423-435.

Prince, M. J. (2017). Persons with invisible disabilities and workplace accommodation: Findings from a scoping literature review. Journal of Vocational Rehabilitation, 46(1), 75-86. https://doi.org/10.3233/JVR-160844

Schomberg, J. (2018) Disability at work: Libraries built to exclude. In, The Politics and Theory of Critical Librarianship, Karen Nicholson \& Maura Seale (Eds).

Schomberg, J., \& Highby, W. (2020). Beyond accommodation: Creating an inclusive workplace for disabled library workers. Library Juice Press: Sacramento CA.

Shuey, K. M., \& Jovic, E. (2013). Disability Accommodation in Nonstandard and Precarious Employment Arrangements. Work and Occupations, 40(2), 174-205. https://doi.org/10.1177/0730888413481030

Smith JA, Flowers P, Larkin M (2009) Interpretative Phenomenological Analysis. London: Sage.

Smith, J. A., \& Osborn, M. (2003). Interpretative phenomenological analysis. In J. A. Smith (Ed.), Qualitative psychology: A practical guide to research methods (p. 51-80). Sage Publications, Inc. 
Statistics Canada. (2019). Workplace accommodations for employees with disabilities in Canada, 2017. http://epe.lac-bac.gc.ca/100/201/301/weekly_acquisitions_list-ef/2019/1939/publications.gc.ca/collections/collection_2019/statcan/89-654-x2019001-eng.pdf

Toth, K. E., \& Dewa, C. S. (2014). Employee Decision-Making About Disclosure of a Mental Disorder at Work. Journal of Occupational Rehabilitation, 24(4), 732-746. https://doi.org/10.1007/s10926-014-9504-y

VanScoy, A, \& Evenstad, S. B. (2015). Intepretive phenomenological analysis for LIS research. Journal of Documentation 71(2), 338-357. 